\title{
Troglitazone Action Is Independent of Adipose Tissue
}

\author{
Charles F. Burant, ${ }^{\star}$ Seamus Sreenan, ${ }^{*}$ Ken-ichi Hirano, ${ }^{*}$ Tzu-Ann C. Tai, ${ }^{\star}$ Jeffrey Lohmiller, ${ }^{\ddagger}$ John Lukens, ${ }^{\ddagger}$ \\ Nicholas O. Davidson, ${ }^{\star}$ Susan Ross, ${ }^{\S}$ and Reed A. Graves ${ }^{\star}$ \\ *Department of Medicine and ${ }^{\ddagger}$ Department of Pathology, The University of Chicago, Chicago, Illinois 60637; and ${ }^{\S}$ Department of \\ Microbiology, Cancer Research Center, University of Pennsylvania, Philadelphia, Pennsylvania 19104
}

\begin{abstract}
We have investigated the antidiabetic action of troglitazone in aP2/DTA mice, whose white and brown fat was virtually eliminated by fat-specific expression of diphtheria toxin A chain. aP2/DTA mice had markedly suppressed serum leptin levels and were hyperphagic, but did not gain excess weight. aP2/DTA mice fed a control diet were hyperlipidemic, hyperglycemic, and had hyperinsulinemia indicative of insulin-resistant diabetes. Treatment with troglitazone alleviated the hyperglycemia, normalized the tolerance to intraperitoneally injected glucose, and significantly decreased elevated insulin levels. Troglitazone also markedly decreased the serum levels of cholesterol, triglycerides, and free fatty acids both in wild-type and aP2/DTA mice. The decrease in serum triglycerides in aP2/DTA mice was due to a marked reduction in VLDL- and LDL-associated triglyceride. In skeletal muscle, triglyceride levels were decreased in aP2/DTA mice compared with controls, but glycogen levels were increased. Troglitazone treatment decreased skeletal muscle, but not hepatic triglyceride and increased hepatic and muscle glycogen content in wild-type mice. Troglitazone decreased muscle glycogen content in aP2/DTA mice without affecting muscle triglyceride levels. The levels of peroxisomal proliferator-activated receptor $\gamma$ mRNA in liver increased slightly in aP2/DTA mice and were not changed by troglitazone treatment. The results demonstrate that insulin resistance and diabetes can occur in animals without significant adipose deposits. Furthermore, troglitazone can alter glucose and lipid metabolism independent of its effects on adipose tissue. (J. Clin. Invest. 1997. 100:2900-2908.) Key words: diabetes - adipose tissue - thiazolidinedione - transgenic • hyperlipidemia
\end{abstract}

\section{Introduction}

Non-insulin-dependent diabetes mellitus (NIDDM) ${ }^{1}$ is characterized by peripheral insulin resistance, increased hepatic

Address correspondence to Charles F. Burant, MC1027, University of Chicago, 5841 S. Maryland Ave., Chicago, IL 60637. Phone: 312-7029233; FAX: 312-702-9194; E-mail: cburant@medicine.bsd.uchicago.edu Received for publication 15 May 1997 and accepted in revised form 16 September 1997.

1. Abbreviations used in this paper: DTA, attenuated form of diphtheria toxin; NIDDM, non-insulin-dependent diabetes mellitus; PPAR, peroxisomal proliferator-activated receptor.

J. Clin. Invest.

(C) The American Society for Clinical Investigation, Inc. 0021-9738/97/12/2900/09 \$2.00

Volume 100, Number 11, December 1997, 2900-2908

http://www.jci.org glucose production, and defects in insulin secretion from pancreatic $\beta$ cells (1). In skeletal muscle, the tissue responsible for up to $90 \%$ of insulin-stimulated glucose disposal, both oxidative and nonoxidative glucose utilization is impaired (1). The increase in hepatic glucose production is associated with increased levels of glucagon and an increased utilization of peripherally derived three carbon gluconeogenic precursors, the latter of which may be due to skeletal muscle insulin resistance (2). The $\beta$ cell dysfunction is due to multiple defects including blunted responses to glucose, changes in insulin secretory patterns, and secretion of incompletely and partially processed insulin (3). Although the underlying cause of these defects in the majority of patients with NIDDM is unknown there is a strong correlation with obesity, especially centripetal obesity (4). Elevated levels of triglycerides and FFA are seen in a majority of patients with obesity, insulin resistance, and $\operatorname{NIDDM}(2,5,6)$. These elevated lipid levels have been implicated in the development of peripheral insulin resistance, increased hepatic glucose production, and $\beta$ cell dysfunction through a variety of mechanisms, including a preferential oxidation of fat vs glucose, changes in phospholipid composition of membranes, and changes in gene expression $(2,5,6)$.

Troglitazone is the first of a new class of agents, the thiazolidinediones, recently approved for the treatment of NIDDM. Troglitazone attenuates the insulin resistance associated with obesity, hypertension, impaired glucose tolerance, and the polycystic ovary syndrome in humans, as well as in several animal models of NIDDM $(7,8)$. In addition to its antidiabetic effects on glucose, troglitazone lowers serum insulin, triglyceride, and FFA levels (9). Although the antidiabetic activity of troglitazone results from improvements in peripheral insulin sensitivity and insulin secretion, it remains unclear whether this is due to direct or indirect effects of the drug on muscle, liver and/or $\beta$ cells.

Thiazolidinediones, including troglitazone, are potent and specific activators of peroxisome proliferator-activated receptor $\gamma$ (PPAR $\gamma$ ), a member of the ligand-activated nuclear hormone receptor superfamily (10). Indeed, there is a striking correlation between the clinical activity of the various thiazolidinediones and their ability to activate PPAR $\gamma(11,12)$. The levels of PPAR $\gamma$ mRNA are 10- to 100-fold higher in adipose tissue compared to other organs (13-15). In cell culture model systems thiazolidinediones act as potent adipogenic agents, (16) reflecting their ability to activate PPARy (11). These observations have led to the suggestion that the antidiabetic actions of the thiazolidinediones result from their ability to alter adipocyte differentiation and/or metabolism resulting in lower serum lipid levels $(11,14)$ and to possibly decrease the secretion of humoral factors from adipocytes, such as TNF- $\alpha$, which would result in the alleviation of insulin resistance $(11,17)$.

Recently, we have reported on transgenic mice in which adipose tissue has been genetically ablated through targeted expression of diphtheria toxin A chain under control of the adipocyte-specific aP2 promoter (18). When treated with mono- 
sodium glutamate (MSG) these animals exhibited profound adipose tissue necrosis, hypertriglyceridemia, and fatty livers (18). We now report that these mice lose virtually all fat tissue as they age, even in the absence of MSG treatment. Furthermore, these mice develop insulin-resistant diabetes as evidenced by elevated serum insulin and elevated blood glucose levels. These animals provided a model to test the hypothesis that adipose tissue is central to the antidiabetic effects of troglitazone.

\section{Methods}

Animals. The construction and breeding of the DTA transgenic mice was previously described (18). In brief, an attenuated form of diphtheria toxin A (DTA) was expressed specifically in brown and white adipose tissue by placing it under the control of the aP2 promoter. Strain No. 8 was used in the current studies. Animals were housed in a conventional facility with a 12:12 light cycle. All experiments were approved by the Institutional Animal Care and Use Committee at the University of Chicago, Chicago, IL.

Diet and troglitazone treatment. Mice of 8-9 mo of age were fed standard pelleted mouse chow (No. 5008; Ralston-Purina Co., St. Louis, MO) until experimentation. Wild-type or heterozygous transgenic mice were randomized and divided to receive ground chow or ground chow containing $16.6 \mathrm{mg}$ troglitazone (Parke-Davis, Ann Arbor, MI) per gram of chow for $5 \mathrm{wk}$. Mice were housed in groups of two to five animals/cage and food consumption was assessed every $2 \mathrm{~d}$. Intake was calculated as an average per mouse per day. Food consumption was unchanged through the duration of the experiment. Before experimentation fasting serum glucose was determined on a blood sample obtained by retroorbital bleeding from anesthetized mice.

Body composition. Before death, mice were fasted for $5 \mathrm{~h}$. The mice were anesthetized with Metofane and serum obtained by cardiac puncture. Organs were removed, weighed, and frozen in liquid nitrogen. Sections of the liver, skeletal muscle, and epididymal and periovarian fat pads (or their remnants) were fixed in Bouin's solution for histological examination.

Intraperitoneal glucose tolerance test (IPGTT). To ascertain glucose tolerance of the aP2/DTA mice, a separate group of aP2/DTA mice was fed either control or troglitazone-containing diet for $5 \mathrm{wk}$. Transgenic or wild type mice were injected with $2 \mathrm{mg} / \mathrm{kg}$ of glucose intraperitoneally and their blood glucose determined from tail vein sampling at $0,30,60$, and $120 \mathrm{~min}$ using a glucometer (HemoCue, Angelholm, Sweden). At autopsy, some 2 wk later, one mouse in the aP2/DTA mice fed control diet group was unexpectedly found to have a significant amount of intraperitoneal fat. Since the genotype of this animal could not be unambiguously related to the IPGTT results, the data from this animal are included in the graph presented in Fig. 1. aP2/ DTA mice used in all other experiments were devoid of detectable adipose tissue.

Serum chemistries. Serum glucose values were determined using a serum glucose analyzer (Yellow Springs Instrument Co., Yellow Springs, $\mathrm{OH}$ ). Serum triglycerides, cholesterol, and free fatty acids were determined using commercial kits (Triglycerides/GB and Cholesterol/HP; Boehringer Mannheim, Indianapolis, IN and NEFA C; Wako Chemicals USA Inc., Richmond VA). Serum leptin levels were performed with a kit (Eli Lilly Co., Indianapolis, IN) according to the manufacturer's protocol. Serum insulin levels were determined by RIA using mouse insulin as a standard (Linco, St. Charles, MO).

Isolation of islets of Langerhans. Islet isolation was accomplished by collagenase digestion and differential centrifugation through Ficoll gradients by procedures previously described (19). After isolation islets were placed into tissue culture plates containing RPMI1640 supplemented with $10 \%$ fetal calf serum, $100 \mu \mathrm{U} / \mathrm{ml}$ penicillin, and $100 \mu \mathrm{g} / \mathrm{ml}$ streptomycin and $11.6 \mathrm{mM}$ glucose, and incubated with $95 \%$ air: $5 \% \mathrm{CO}_{2}$ at $37^{\circ} \mathrm{C}$ in a humidified incubator for $2 \mathrm{~h}$.
Determination of insulin release from perifused islets. Secretion of insulin from perifused islets was measured using a temperature-controlled multichamber perifusion system (ACUSYST-S; Cellex Biosciences, Inc., Minneapolis, MN). Groups of 25 islets were suspended in BioGel P2 beads and modified KRB and placed in four parallel perifusion chambers. KRB contained $2 \mathrm{mM}$ glucose and $5 \mathrm{mg} / \mathrm{ml}$ bovine serum albumin. After an equilibration period during which islets were perifused for $30 \mathrm{~min}$ at $37^{\circ} \mathrm{C}$ with $\mathrm{KRB}$ containing $2 \mathrm{mM}$ glucose, sampling of the effluent perifusate was initiated at 1-min intervals. During the first $5 \mathrm{~min} \mathrm{KRB}$ containing $2 \mathrm{mM}$ glucose was perifused, after which the perifusate glucose concentration was increased to $20 \mathrm{mM}$ glucose. Effluent perifusate was collected for a further 15 min. The insulin concentration of the effluent perifusate was measured by RIA as described (20) and expressed as $\mu \mathrm{U}$ insulin/ml per 25 islets.

Agarose gel electrophoresis. Serum samples $(2 \mu \mathrm{l})$ were electrophoresed on $1 \%$ agarose gels as recommended by the manufacturer (Lipoprotein system; CIBA-Corning, Alameda, CA). The gels were dried and stained for lipid with Fat Red 7B.

Lipoprotein profiles. Pooled serum samples from three transgenic mice fed control diets and three transgenic mice fed troglitazone were chromatographed on two sequential Superose 6 10/50 HR columns (Pharmacia Fine Chemicals, Piscataway, NJ) equilibrated with PBS. The column was eluted at a flow rate of $0.2 \mathrm{ml} / \mathrm{min}$ and $300.8-\mathrm{ml}$ fractions collected. Cholesterol and triglyceride were measured on $200-\mu l$ samples of each fraction using enzymatic kits according to the manufacturer's directions (cholesterol, total; [Sigma Chemical Co., St. Louis, MO] and triglycerides/GB [Boehringer Mannheim]).

Tissue triglyceride and glycogen content. For determination of total triglyceride content, $\sim 50-\mathrm{mg}$ fragments of liver or gastrocnemius were powdered under liquid nitrogen and extracted for $16 \mathrm{~h}$ at $4^{\circ} \mathrm{C}$ in $4 \mathrm{ml} \mathrm{CHCl}: \mathrm{MeOH}(2: 1)$ after which $2 \mathrm{ml}$ of $0.6 \% \mathrm{NaCl}$ was added and the solution centrifuged at 2,000 $\mathrm{g}$ for $20 \mathrm{~min}$ (21). The organic layer was removed and dried under a stream of argon. The resulting pellet was dissolved in phosphate buffered saline containing $1 \%$ Triton X-100 and the triglyceride content determined as described above.

For determination of glycogen, 50-mg fragments of liver or gastrocnemius were dissolved in $1 \mathrm{ml}$ of $30 \% \mathrm{KOH}$ (15). The glycogen was precipitated by the sequential addition of $100 \mu \mathrm{l}$ of $2 \mathrm{M} \mathrm{Na}_{2} \mathrm{SO}_{4}$ and $1 \mathrm{ml} \mathrm{EtOH}$ at $-20^{\circ} \mathrm{C}$ for $16 \mathrm{~h}$. The pellet was collected and washed twice with $1 \mathrm{ml} \mathrm{KOH}$ and $1 \mathrm{ml}$ of EtOH and hydrolyzed in $0.5 \mathrm{ml}$ $4 \mathrm{~N} \mathrm{H}_{2} \mathrm{SO}_{4}$ at $100^{\circ} \mathrm{C}$ for $1 \mathrm{~h}$. The solution was neutralized and glucose determined by the glucose oxidase method (22).

Northern blots. Total RNA was isolated from liver and skeletal muscle using the Trizol reagent (Gibco-BRL, Gaithersburg, MD). Equal amounts of RNA from three to five animals were combined and $20 \mu \mathrm{g}$ RNA was electrophoresed on a $1 \%$ agarose-formaldehyde gel, transferred to nylon, and probed with a ${ }^{32} \mathrm{P}$-labeled fragment of mouse PPAR $\gamma$ which detects both PPAR $\gamma 1$ and PPAR $\gamma 2$ (13). The blots were washed in $0.1 \%$ SDS and $0.1 \times \mathrm{SSC}$ at $55^{\circ} \mathrm{C}$. Quantitative analysis was performed on a phosphoimager (Molecular Dynamics, Sunnyvale, CA). Blots were normalized after hybridization to 36B4 (23).

Statistical analysis. Differences among groups were determined by Student's $t$ test or analysis of variance using a SAS system for the PC with Tukey's Studentized range test applied post-hoc.

\section{Results}

As previously reported, young (2 mo) aP2/DTA transgenic mice (strain No. 8) have relatively normal amounts of adipose tissue (18). Adipose tissue depots begin to diminish spontaneously at 5-6 mo of age and histological examination demonstrated extensive atrophy and necrosis of fat, characterized by monocytic infiltration (data not shown). This adipose tissue necrosis is similar to the necrosis observed previously in MSGtreated young mice of this strain (18). By 8-10 mo of age, untreated mice have no visible subcutaneous or intraabdominal 


\begin{tabular}{|c|c|c|c|c|}
\hline Treatment group & $\begin{array}{c}\text { Wild type, } \\
\text { no troglitazone }\end{array}$ & $\begin{array}{l}\text { Wild type, } \\
\text { troglitazone }\end{array}$ & $\begin{array}{c}\text { aP2/DTA, } \\
\text { no troglitazone }\end{array}$ & $\begin{array}{l}\text { aP2/DTA, } \\
\text { troglitazone }\end{array}$ \\
\hline$(n)$ & 6 & 6 & 7 & 7 \\
\hline $\operatorname{Sex}(M / F)$ & $(2 / 4)$ & $(2 / 4)$ & $(3 / 4)$ & $(2 / 5)$ \\
\hline Prestudy body weight $(\mathrm{g})$ & $40.1 \pm 3.4$ & $37.5 \pm 2.1$ & $41.1 \pm 2.3$ & $39.4 \pm 2.2$ \\
\hline Prestudy serum glucose (mg/dl) & $133.7 \pm 6.2$ & $121.7 \pm 10.9$ & $245.2 \pm 30.4^{*}$ & $287.6 \pm 36.4^{*}$ \\
\hline Chow consumption (g/mouse/day) & $2.3 \pm 0.5$ & $2.5 \pm 0.4$ & $5.4 \pm 0.6^{*}$ & $5.5 \pm 0.7^{*}$ \\
\hline Poststudy body weight (g) & $36.5 \pm 3.3$ & $35.3 \pm 2.8$ & $40.1 \pm 2.4$ & $37.0 \pm 2.3$ \\
\hline Brown fat $(\mathrm{g})$ & $0.11 \pm 0.01$ & $0.10 \pm 0.01$ & - & - \\
\hline White fat $(\mathrm{g})$ & $2.94 \pm 0.78$ & $2.84 \pm 1.38$ & $0.24 \pm 0.03 *$ & $0.18 \pm 0.02 *$ \\
\hline Liver $(\mathrm{g})$ & $1.56 \pm 0.18$ & $1.29 \pm 0.25$ & $6.53 \pm 1.06^{*}$ & $5.36 \pm 0.75^{*}$ \\
\hline Pancreas (g) & $0.40 \pm 0.02$ & $0.40 \pm 0.08$ & $0.75 \pm 0.07 *$ & $0.62 \pm 0.06^{*}$ \\
\hline Heart (g) & $0.13 \pm 0.01$ & $0.17 \pm 0.04$ & $0.21 \pm 0.01 *$ & $0.20 \pm 0.01 *$ \\
\hline
\end{tabular}

$* P<0.05$ vs. wild type, no troglitazone.

adipose tissue (data not shown). This loss of adipose tissue was accompanied by a progressive increase in serum glucose and insulin levels and culminated in the development of frank diabetes at $\sim 8$ mo of age (Table I and data not shown).

The finding of insulin-resistant diabetes in aP2/DTA mice provided an opportunity to examine the effects of the insulinsensitizing agent troglitazone, in the absence of significant amounts of adipose tissue depots. Wild-type and aP2/DTA mice were fed ground chow with or without troglitazone for $5 \mathrm{wk}$. To determine the effect of troglitazone treatment in the whole animal, intraperitoneal glucose tolerance tests were performed on 6-h fasted, control diet-fed wild-type mice and aP2/DTA mice fed either control diet or troglitazone containing diet. There was a significant elevation in the blood glucose at all time points in the control diet-fed aP2/DTA mice compared with wild-type mice. Treatment with troglitazone normalized the glucose tolerance of the aP2/DTA mice (Fig. 1).

Transgenic mice consumed about 2.3 times more food than their wild-type counterparts; addition of troglitazone to the diet did not change the consumption pattern in either wildtype or aP2/DTA transgenic animals (Table I). The hyperphagia in aP2/DTA mice resulted in increased troglitazone consumption by the transgenic compared with wild-type mice (91.8 mg/day vs $41.5 \mathrm{mg} /$ day). The body weights of the mice were no different in any of the groups (Table I). Gonadal fat pads from both control and troglitazone-fed aP2/DTA mice were fibrotic as previously seen (18) and interscapular brown fat was undetectable. The livers of the transgenic aP2/DTA mice were about threefold larger than wild-types and were grossly engorged with fat (Table I). Troglitazone-treated aP2/ DTA transgenic mice revealed a trend towards smaller liver size which was not statistically significant (Table I). The pancreas of the transgenic mice was twofold larger than wild-type; troglitazone supplementation decreased the pancreas size in aP2/DTA but not wild-type mice (Table I). Finally, the weight of the hearts in the transgenic animals were larger than the wild-type controls (Table I).

The observed increased food consumption may be due to the absence of fat and leptin deficiency. Serum leptin levels were markedly reduced in aP2/DTA as compared to wild-type mice (Fig. $2 A$ ). The serum leptin values in the aP2/DTA mice may be an overestimate, as values were below detection in two mice from both the control and troglitazone diet groups, but were scored as being at the detection limit $(0.2 \mathrm{ng} / \mathrm{ml})$. Troglitazone addition to the diet resulted in a $45 \%$ reduction in the circulating leptin concentration in wild-type mice as has been previously reported (24) but did not increase the levels in aP2/ DTA mice (Fig. $2 \mathrm{~A}$ ). To further examine the depletion of adipose tissue in the transgenic animals, total RNA was prepared from the perigonadal fat pads from wild-type mice and from the remnant tissue from the aP2/DTA mice and probed for PPAR $\gamma$. PPAR $\gamma$ mRNA levels were $\sim 8 \%$ of the levels found

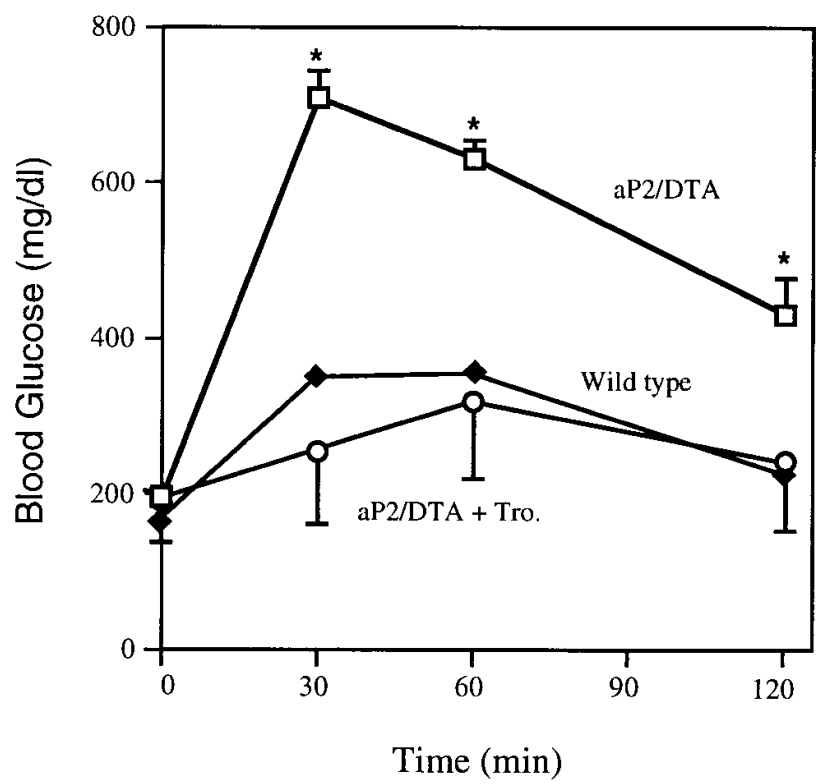

Figure 1. Intraperitoneal glucose tolerance tests in wild-type and aP2/DTA mice. Mice were injected with $2 \mathrm{mg} / \mathrm{kg}$ of glucose and the blood glucose levels determined at the indicated time points. wild-type mice fed control diet; $\square-\square$, aP2/DTA mice fed control diet; $\bigcirc-\bigcirc$, aP2/DTA mice fed troglitazone diet. The $n$ for each time point is $3-7$. * Significantly different from wild-type values $(P<0.05)$. 
A

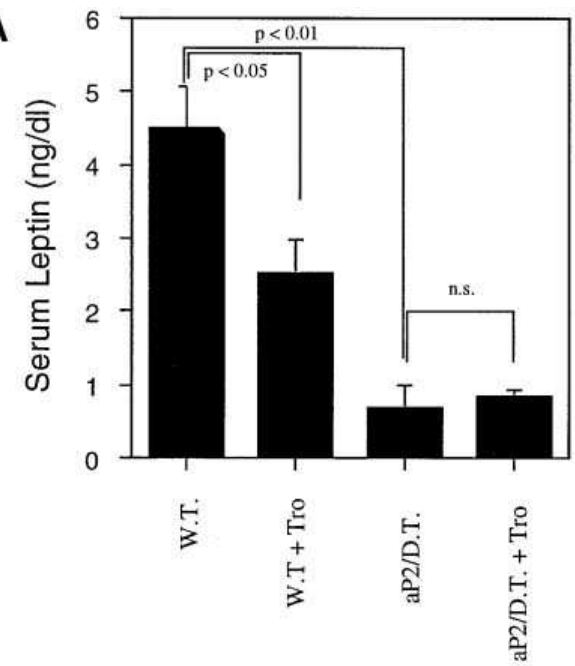

B

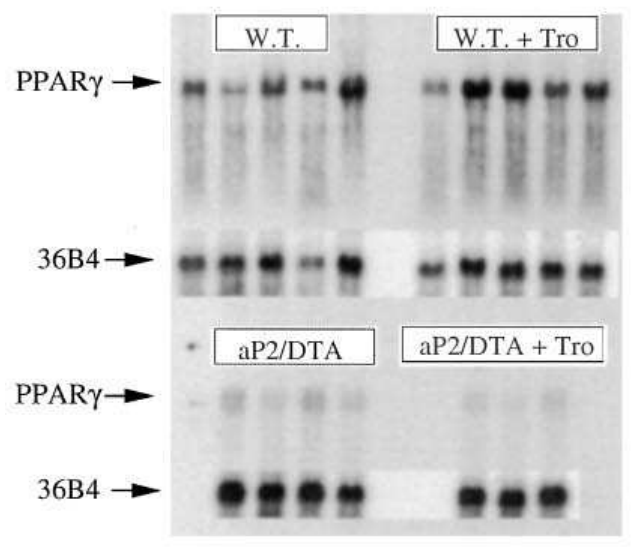

C

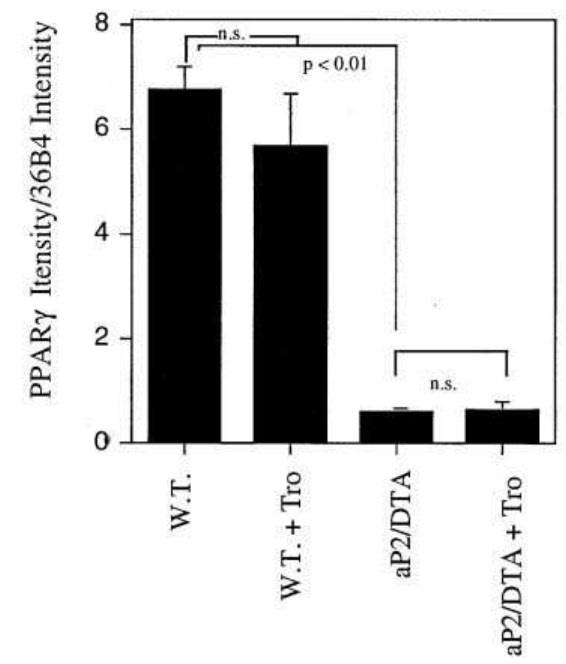

Figure 2. Serum leptin levels and PPAR $\gamma$ mRNA form perigonadal tissue in wild-type and aP2/DTA mice. $(A)$ Fasting serum leptin levels. (B) Autoradiogram of the indicated samples. Autoradiograms of the 36B4-probed filters are inserted as indicated in the figure. Total RNA from the indicated groups of animals was separated on agarose gels, transferred to nylon membranes, and probed with ${ }^{32} \mathrm{P}$-labeled mouse PPAR $\gamma$ and 36B4 and quantitated by phosphoimaging. $(C)$ Quantitation of relative levels of PPAR $\gamma$ mRNA levels from each group normalized to $36 \mathrm{~B} 4$ levels. $n=$ three to five mice in each group. Significant differences are indicated by $P$ values. $n=$ three to seven determinations for each point.
A

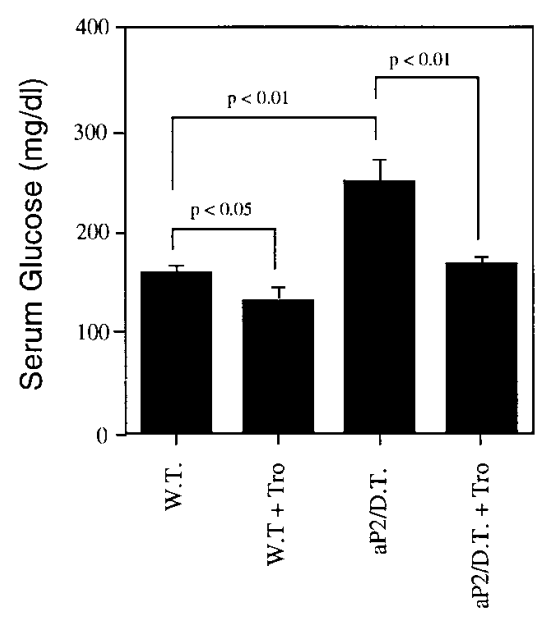

B

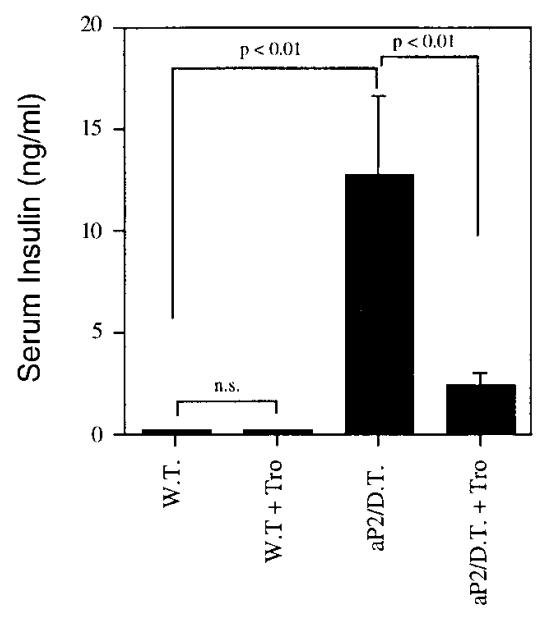

C

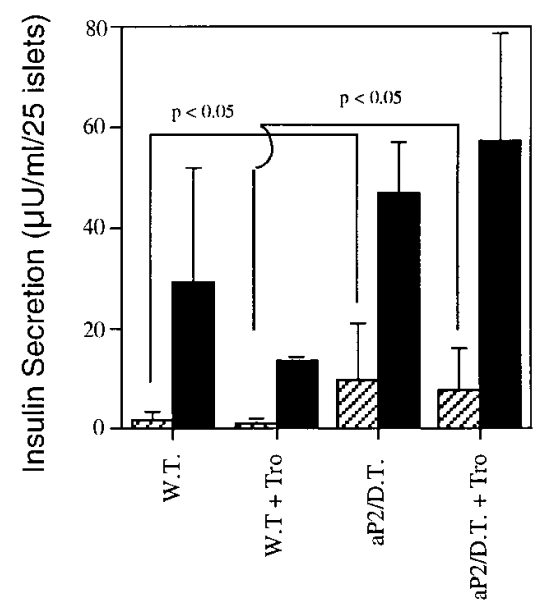

Figure 3. Serum glucose and insulin levels and insulin secretion from isolated islets from wild-type and aP2/DTA mice. $(A)$ Fasting serum glucose; $(B)$ Fasting serum insulin. Assays were performed on serum after feeding control or troglitazone (Tro) diets for $5 \mathrm{wk}$. Significant differences are indicated by $P$ values. $n=$ five to seven determinations for each point. $(C)$ Insulin secretion from isolated, perifused islets of Langerhans. Islets were isolated from wild-type mice or aP2/ DTA mice with and without troglitazone treatment and subjected to perifusion with a solution containing $2 \mathrm{mM}$ glucose for $5 \mathrm{~min}$ (hatched bars) after which the glucose in the perfusate was increased to $20 \mathrm{mM}$ (solid bars). Each fraction was assessed for insulin by RIA using a mouse standard in duplicate. $n=3-5$ for each point. Significantly different values between groups are indicated by $P$ values. 
in the wild-type fat (Fig. 2, $B$ and $C$ ). Importantly, troglitazone had no effect on the levels of PPAR $\gamma$ mRNA from either the wild-type or aP2/DTA mice (Fig. 2, $B$ and $C$ ).

aP2/DTA mice fed control diet were hyperinsulinemic and hyperglycemic at the end of the 5-wk feeding (Fig. 3, $A$ and $B$ ). Troglitazone treatment slightly decreased the serum glucose levels in wild-type mice (Fig. $3 \mathrm{~A}$ ). However, the serum glucose levels in the troglitazone-treated aP2/DTA mice were substantially reduced, and were comparable to the levels observed in wild-type mice (Fig. $3 \mathrm{~A}$ ). This reduction in glucose levels was accompanied by a fivefold reduction in serum insulin levels (Fig. 3 B). Although serum insulin did not fall to wildtype levels, these results and the results of the intraperitoneal glucose tolerance test are indicative of a substantial increase in insulin sensitivity.

We observed significant islet hypertrophy in the pancreas of aP2/DTA mice (data not shown) which is reflected in the increase in pancreas weight in aP2/DTA mice (Table I). Reflecting the islet hypertrophy, increases in basal insulin secretion by isolated islets from aP2/DTA mice was seen (Fig. $3 C$ ). Troglitazone did not significantly affect the insulin secretion rates in either group of animals.

The ability of troglitazone to influence lipid and cholesterol metabolism in the nearly complete absence of adipose tissue is shown in Fig. 4. The control diet-fed aP2/DTA mice showed significant elevations in fasting serum triglyceride and cholesterol levels, though the levels of serum FFA were not altered in aP2/DTA mice. Other experiments demonstrated that FFA levels were twofold higher in the postprandial state compared to wild-type animals ( $3.2 \pm 0.5$ vs $1.5 \pm 0.4 \mu \mathrm{M}, n=3$ each). Troglitazone treatment markedly reduced fasting serum triglyceride and cholesterol levels in aP2/DTA mice (Fig. 4, $A$ and $B$ ). Indeed, the serum triglyceride levels were reduced to the levels observed in troglitazone-treated wild-type mice and were below the levels observed in the chow-fed wild-type mice. We also observed that serum FFA were comparably reduced by troglitazone in both the wild-type and aP2/DTA mice (Fig. 4C).

We next examined the triglyceride and cholesterol content of the various lipoprotein particles. Agarose gel electrophoresis demonstrated that troglitazone treatment resulted in a marked decrease in neutral lipid staining in bands with $\beta$ and pre- $\beta$ mobility in serum from both the wild-type and aP2/DTA mice (Fig. $5 A$ ). To determine more precisely the effect of troglitazone, FPLC fractionation was performed on pooled serum samples from aP2/DTA transgenic animals fed control or troglitazone-containing diets. As shown in Fig. $5 \mathrm{~B}$, there was a small decrease in HDL cholesterol after troglitazone treatment with minimal changes in LDL cholesterol content. In marked contrast, there was almost complete elimination of VLDL- and LDL-associated triglyceride (Fig. 5 C). This demonstrates that the decrease in neutral lipid staining observed on agarose electrophoresis most likely corresponds to a decrease in triglyceride content of VLDL and LDL.

Consistent with their gross appearance, the triglyceride content of livers from aP2/DTA mice was increased about fivefold over the controls (Fig. $6 A$ ). Troglitazone had no effect on hepatic triglyceride content from control or aP2/DTA mice, but significantly lowered the triglyceride content in gastrocnemius muscle samples from wild-type mice (Fig. $6 B$ ). aP2/DTA skeletal muscle associated triglyceride was $\sim 35 \%$ of wild-type and was not influenced by troglitazone treatment (Fig. $6 \mathrm{~B}$ ). Hepatic glycogen content in wild-type mice was not influenced
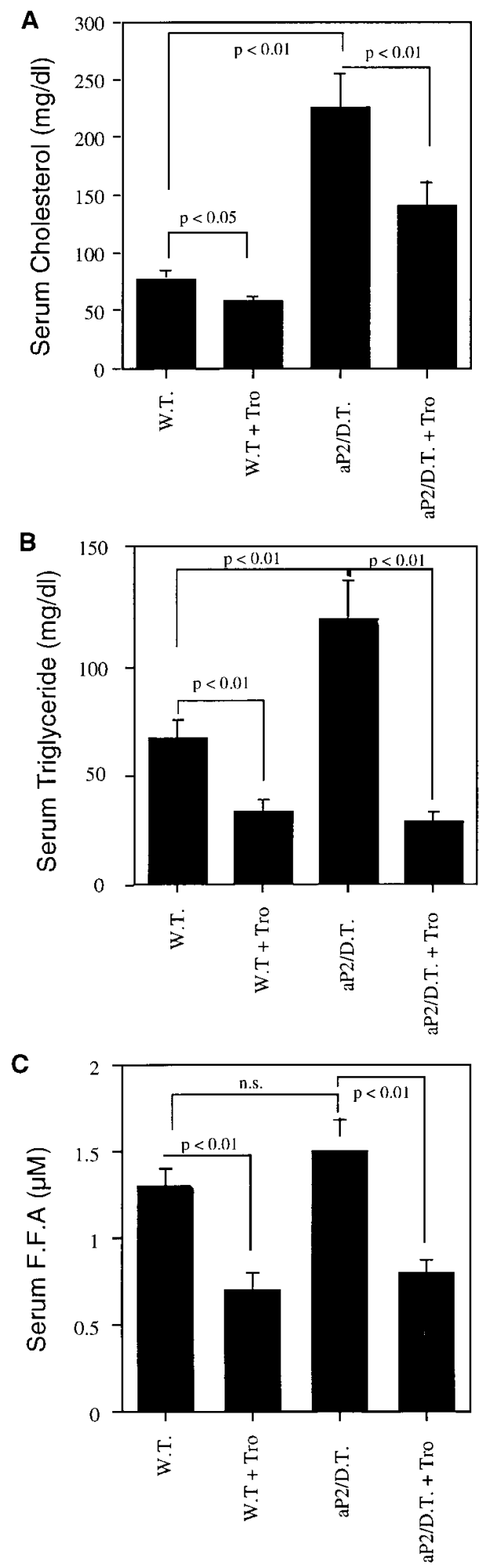

Figure 4. Serum cholesterol, triglyceride, and free fatty acid levels in wild-type and aP2/DTA mice. Serum cholesterol $(A)$, triglycerides $(B)$, and free fatty acids $(C)$ were determined after a 6-h fast. Significant differences are indicated by $P$ values. $n=$ five to seven determinations for each point. 

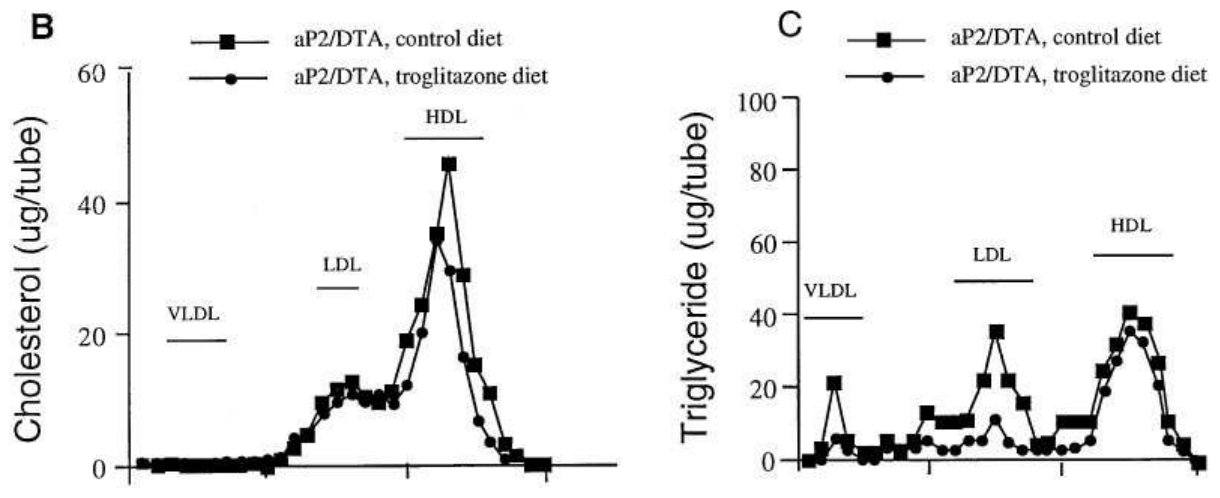

Figure 5. Effect of troglitazone on serum lipid profiles in wild-type and aP2/DTA mice. (A) Samples of serum from the indicated fasted mice were subjected to agarose gel electrophoresis and stained with Fat Red 7B. The arrow indicated the relative mobility of the indicated lipoprotein. $(B)$ FPLC profile of pooled serum from three aP2/DTA mice receiving either control or troglitazone containing diets. The position of elution for VLDL, LDL, and HDL lipoproteins is indicated.

by troglitazone (Fig. $6 C$ ). However, hepatic glycogen content in aP2/DTA transgenic mice was increased twofold compared with controls (Fig. $6 C$ ) and was slightly decreased by troglitazone treatment. By contrast, troglitazone treatment increased the glycogen content of skeletal muscle in wild-type mice (Fig. $6 \mathrm{D}$ ) by $\sim 40 \%$. The muscle glycogen content of aP2/DTA animals was increased nearly twofold compared with wild-type, and troglitazone treatment decreased these levels to near control values (Fig. $6 \mathrm{D}$ ).

Thiazolidinediones can bind PPAR $\gamma$ and activate transcription through the PPAR response elements (11). As previously reported, the levels of PPAR $\gamma$ mRNA was very low in liver of wild-type mice (Fig. 7) as compared to adipose tissue (7-10\% of adipose tissue levels, not shown). Troglitazone treatment resulted in $\sim 25 \%$ reduction in PPAR $\gamma$ mRNA levels in the wild-type animals. The levels of PPAR $\gamma$ mRNA increased $\sim 30 \%$ in the livers of aP2/DTA transgenic mice compared with wild type, and troglitazone treatment increased these mRNA levels by $\sim 15 \%$ in aP2/DTA animals. PPAR $\gamma$ mRNA levels in skeletal muscle was below the limit of detection in all groups of animals (not shown).

\section{Discussion}

The data presented demonstrate that the development of insulin resistance and the actions of troglitazone to alleviate insulin resistance can occur independent of adipose tissue. The remnant perigonadal tissue weight and PPAR $\gamma$ mRNA levels detected in aP2/DTA mice were each $10 \%$ or less than that observed in wild-type animals (Table I and Fig. 2, $B$ and $C$ ). In addition to residual adipose cells, the PPAR $\gamma$ mRNA may have come from supporting or inflammatory cells (25) associated with the necrotic perigonadal tissue. Serum leptin levels were at the limit of detection in the majority of the aP2/DTA mice and no increases occurred when troglitazone was added to the diet, suggesting no stimulation of new adipocyte formation (Fig. 2 A). Indeed, it may be expected that troglitazone treatment would increase fat cell death since the aP2 promoter driving the diphtheria toxin A chain in the transgenic construct contains two PPAR $\gamma$ response elements $(13,18)$. Although we cannot completely rule out the possibility of microscopic depots of adipose tissue in aP2/DTA mice, our study clearly demonstrates that the antidiabetic action of the thiazolidinediones in these mice do not necessarily require large adipose depots. However, our studies do not rule out a potential (and substantial) role for adipose tissue in the antidiabetic actions of thiazolidinediones in obesity-linked diabetes.

As obesity develops in humans and in most animal models of diabetes, triglyceride, free fatty acid, and insulin levels rise concurrent with the development of insulin resistance $(2,4,5)$. Although the aP2/DTA mouse model is obviously very different than obesity-linked insulin resistance models, they do share common metabolic abnormalities. For example, aP2/DTA mice have fasting hypertriglycerideimia and hypercholesterolemia compared to their wild-type counterparts and develop insulin resistance. In obesity-related insulin resistance, the increased availability of lipid has been suggested to play a role in decreased capacity of skeletal muscle to take up glucose, perhaps through the activation of the Randle cycle $(4,5)$ or a more proximal action on glucose utilization (26). A further decrease in glucose tolerance may be due to increased free fatty acid delivery to the liver, stimulating hepatic gluconeogenesis (4). Additionally, it has been suggested that humoral factors, such as $\mathrm{TNF}-\alpha$, generated by the expanded adipose mass in obesity may directly cause insulin resistance (17). While the former mechanism may be operative in the aP2/DTA mice, the data presented here demonstrate that insulin resistance can occur in hyperlipidemic animals that lack substantial amounts of adipose tissue and thus does not necessarily require the secretion of humoral factors from adipocytes. 
A

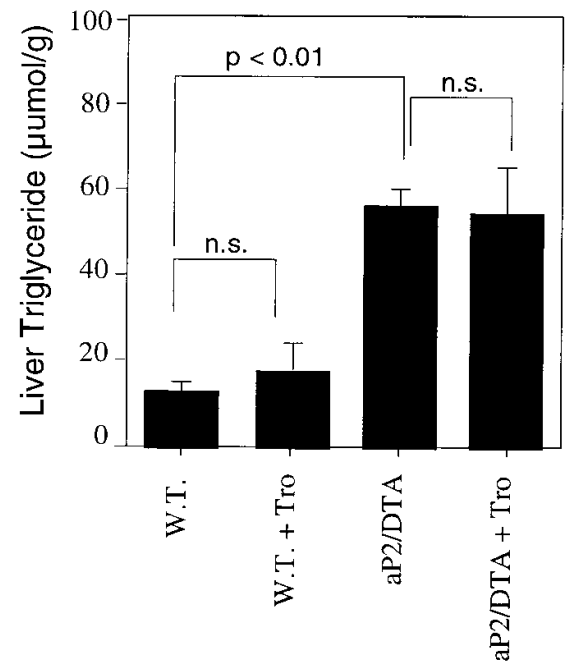

C

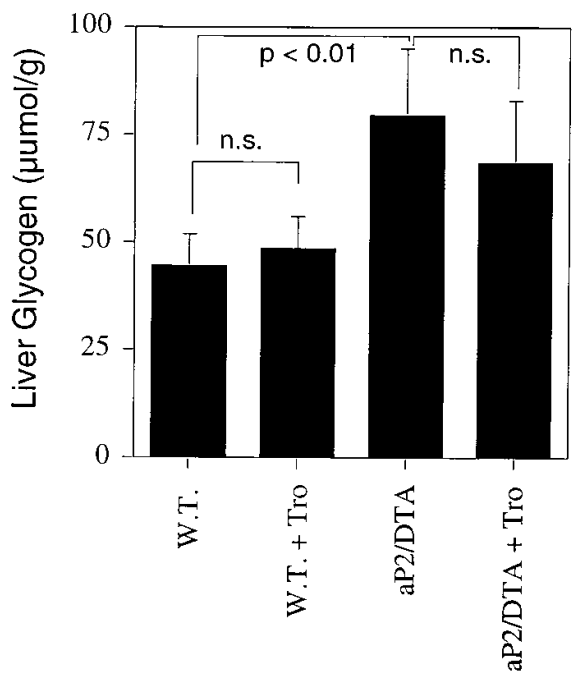

B

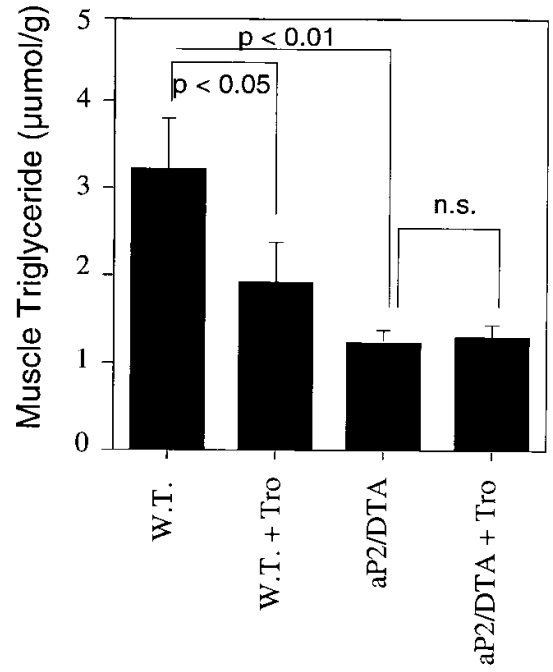

D

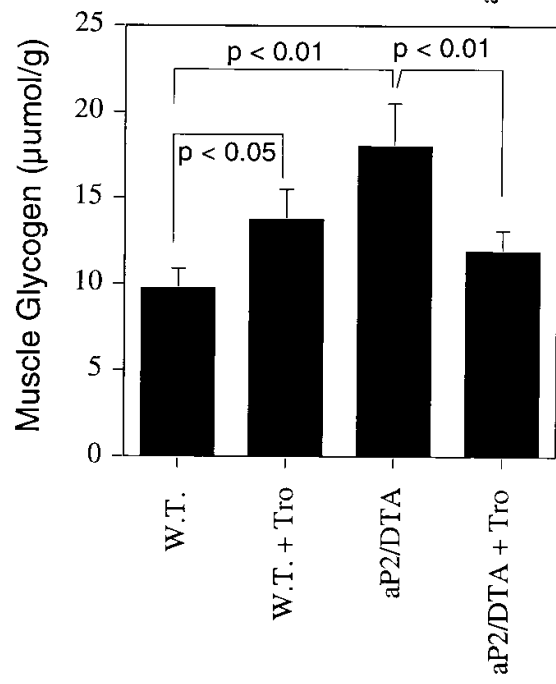

Figure 6. Liver and muscle triglyceride and glycogen content in wild-type and aP2/DTA mice. Fragments of liver $(A$ and $C$ ) or gastrocnemius muscle $(B$ and $D)(\sim 50$ $\mathrm{mg}$ each) were extracted and the mass of triglyceride ( $A$ and $B)$ and glycogen $(C$ and $D$ ) determined as described in Methods. Significant differences are indicated by $P$ values. $n=$ five to seven determinations for each point.
aP2/DTA mice lose adipose tissue and become hyperphagic, likely in part due to a decrease in leptin production (27). Since the aP2/DTA mice do not gain weight, the disposition of the excess energy consumed by aP2/DTA mice is uncertain. Certainly, some of the ingested energy is deposited as fat in the liver (Fig. 6) and we have detected glycosuria in the aP2/DTA mice, however, the glycosuria is eliminated by troglitazone treatment (data not shown) without an increase in body weight (Table I). Generally, we observed less physical activity in the transgenic mice and did not recognize evidence of malabsorption such as diarrhea. The absence of brown adipose tissue makes it unlikely that classical uncoupling-oxidative phosphorylation is occurring. It will be of interest to examine the role of UCP2 (28) and UCP3 (29), mitochondrial uncoupling proteins expressed in multiple tissues, in the apparent adaptation by aP2/DTA mice.

The molecular mechanism by which troglitazone altered the metabolic milieu in the aP2/DTA transgenic mice is unknown. Among the known actions of the thiazolidinediones are their ability to bind and activate PPAR $\gamma$, a member of the nuclear hormone receptor family of transcription factors (10, 11). Because PPAR $\gamma$ levels are highest in adipose tissue, it has been suggested that the improved metabolic profile of liver and skeletal muscle after troglitazone treatment is secondary to direct effects of the drug on adipocytes or other actions mediated through white or brown adipose tissue $(11,14)$. We observed a small rise in the level of PPAR $\gamma$ mRNA expression in liver of aP2/DTA mice (Fig. 7), however PPAR $\gamma$ mRNA expression was undetectable in skeletal muscle by standard Northern blotting. The increase in PPAR $\gamma$ mRNA levels in the livers of hyperlipidemic, hyperphagic aP2/DTA mice is similar to that seen in mouse models of obesity, hyperphagia, and hyperlipidemia associated with brown fat ablation and gold thioglucose-induced obesity (30). Because treatment with troglitazone markedly improves the glucose tolerance of the aP2/DTA mice, as assessed by the intraperitoneal glucose tolerance test (Fig. 1), an improvement in skeletal muscle insulin sensitivity is proposed. Additional troglitazone-mediated effects in the livers of aP2/DTA mice, which lead to decreased hepatic glucose production and the elimination of glucose toxicity (31) may also play a role in the improvement of the metabolic milieu of the aP2/DTA mice. Possible mechanisms for troglitazone action directly in skeletal muscle include either activation of the small levels of PPAR $\gamma$ or activation of an alternative signal transduction pathway secondary to troglitazone treatment. 


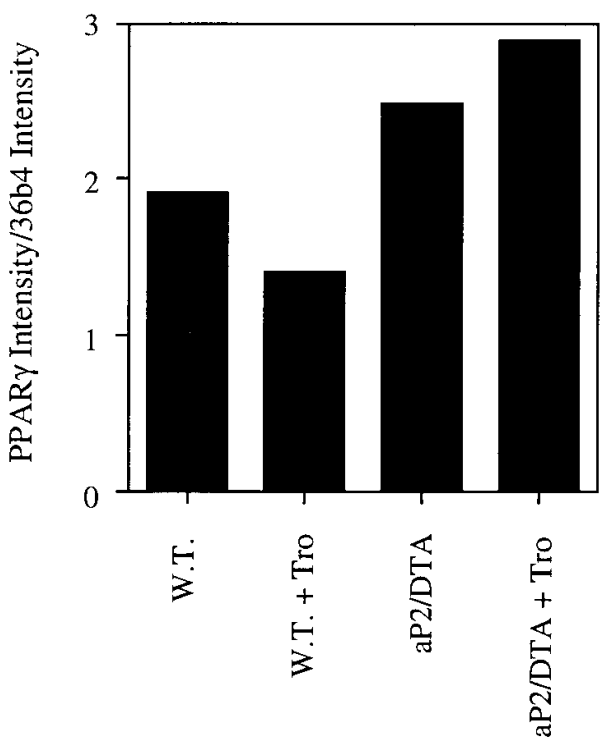

Figure 7. PPAR $\gamma$ mRNA content of liver in wild-type and aP2/DTA mice. Pooled samples of RNA from the indicated groups of animals were separated and transferred to nylon membranes and probed with ${ }^{32} \mathrm{P}$-labeled mouse PPAR $\gamma$ and 36B4 and quantitated by phosphoimaging. The data illustrate the relative levels of PPAR $\gamma$ mRNA from each group normalized to 36B4 levels. $n=$ five mice in each group.

Troglitazone is known to decrease circulating VLDL levels through mechanisms thought to include increased peripheral clearance and decreased hepatic glucose production $(32,33)$. The hepatomegaly and steatosis seen in aP2/DTA mice likely occurred secondary to increased delivery of dietary free fatty acids, coupled with augmented triglyceride storage. Troglitazone tended to decrease the liver size in the transgenic mice (although this was not statistically significant) and the drug markedly reduced peripheral FFA, triglyceride, and cholesterol levels (Fig. 4). The small decrease in cholesterol was mainly due to decreased HDL cholesterol (the primary cholesterol carrier in mice). The most marked change in the lipid profile induced by troglitazone was the virtual elimination of triglyceride from the VLDL and LDL fractions in the aP2/ DTA-transgenic mice (Fig. 5). While decreases in the production of VLDL by liver due to troglitazone merit consideration, the observation that the liver triglyceride content was not affected by troglitazone treatment in the aP2/DTA mice concurrent with marked decrease in VLDL and LDL triglycerides suggests that the primary action of the drug is to enhance peripheral clearance of triglyceride.

There are reports of an association between muscle triglyceride levels and insulin resistance $(34,35)$. After troglitazone treatment the triglyceride content of muscle in wild-type mice decreased by about half, however there was a decrease in muscle-associated triglyceride in gastrocnemius muscle in untreated aP2/DTA and these animals were severely insulin resistant (Fig. 6). To be sure, some of the decrease in triglycerides was due to a decrease in the levels of perimyocyte fat due to transgene-mediated adipose depletion. The increased glycogen stores in the muscle of aP2/DTA mice could be explained by the increased lipid delivery to skeletal muscle leading to a sparing of glucose oxidation. Indeed, an increase in skeletal muscle uptake of free fatty acids by overexpression of lipoprotein lipase in skeletal muscle is associated with increased accumulation of glycogen particles in the myocytes (36). Troglitazone treatment did not change the levels of triglyceride associated with aP2/DTA skeletal muscle but did markedly lower the levels of glycogen. Whether the decrease in circulating triglycerides, or other alterations in the oxidation of fats after troglitazone treatment leads to an improvement in glucose oxidation in muscle is unclear. It should be noted that the levels of triglyceride detected in skeletal muscle from aP2/ DTA mice were at the lower level of detection in our assay and subtle changes secondary to troglitazone treatment may have gone undetected.

Finally, the depletion of adipose tissue with aging in aP2/ DTA mice mimics the Lawrence Syndrome form of lipoatrophic diabetes (37). These patients have delayed lipoatrophy and a progressive increase in insulin resistance. This form of lipoatrophic diabetes is not associated with mutations in the insulin receptor (38), and in general is thought to be a sporadic disease although familial clustering and consanguinity have been reported (39). Given the effectiveness of troglitazone in aP2/DTA mice it will be of great interest to evaluate the clinical effectiveness of troglitazone therapy in these patients.

In summary, mice lacking adipose tissue are hyperphagic but are able to adapt to the increased nutrient load as witnessed by the maintenance of a similar weight despite the increased energy intake. In addition, it is clear that the action of the hypoglycemic agent troglitazone does not require significant levels of adipose tissue to improve insulin sensitivity. We present data that suggest a major action of troglitazone is in skeletal muscle, perhaps modifying the way in which skeletal muscle utilizes lipids. As agents which simply lower triglyceride and free fatty acids do not necessarily promote increased insulin sensitivity (40), we propose that the improved utilization of lipids by skeletal muscle with troglitazone treatment lowers peripheral FFA and triglyceride levels in obesityrelated diabetes and allows a secondary improvement in glucose utilization.

\section{Acknowledgments}

The authors would like to thank Paul Rue for performing leptin and insulin assays, Marta de Olano Vela for expert technical assistance, and Kenneth Polonsky for helpful comments and suggestions and long standing support.

These studies were supported by The National Institute of Diabetes and Digestive and Kidney Diseases Grant DK-02170 (C.F. Burant), HL-38180, HL-18577, DK-42086 (N.O. Davidson), DK-50103 (R.A. Graves), DK-26678 to the Clinical Nutrition Research Unit of the University of Chicago, Chicago, IL, and DK-20595 to the Diabetes Research and Training Center (DRTC) at the University of Chicago, The American Heart Association (S.R. Ross), and National Institutes of Health DK-19525 to the DRTC at the University of Pennsylvania, Philadelphia, PA.

\section{References}

1. DeFronzo, R.A. 1988. Lilly lecture. The triumvirate: $\beta$-cell, muscle, liver. A collusion responsible for NIDDM. Diabetes. 37:667-687.

2. Moller, D.E. 1993. Insulin Resistance. John Wiley \& Sons, Ltd., London. 143-186.

3. Polonsky, K.S. 1995. Lilly lecture. The beta-cell in diabetes: from molecular genetics to clinical research. Diabetes. 44:705-717.

4. Boden, G. 1997. Role of fatty acids in the pathogenesis of insulin resistance and NIDDM. Diabetes. 46:3-10.

5. McGarry, J.D. 1994. Disordered metabolism in diabetes: have we under- 
emphasized the fat component? J. Cell. Biochem. 55:29-38.

6. Reaven, G.M. 1995. The fourth musketeer-from Alexandre Dumas to Claude Bernard. Diabetologia. 38:3-13.

7. Saltiel, A.R., and J.M. Olefsky. 1996. Thiazolidinediones in the treatment of insulin resistance and type II diabetes. Diabetes. 45:1661-1669.

8. Sreenan, S., J. Sturis, W. Pugh, C.F. Burant, and K.S. Polonsky. 1996. Prevention of hyperglycemia in the Zucker diabetic fatty rat by treatment with metformin and troglitazone. Am. J. Physiol. 271:E742-774.

9. Ghazzi, M.N., J.E. Perez, T.K. Antonucci, J.H. Driscoll, S.M. Huang, B.W. Faja, The Troglitazone Study Group, and R.W. Whitcomb. 1997. Cardiac and glycemic benefit of troglitazone treatment in NIDDM. Diabetes. 46:433-439.

10. Spiegelman, B.M., and J.S. Flier. 1996. Adipogenesis and obesity: rounding out the big picture. Cell. 87:377-389.

11. Lehmann, J.M., L.B. Moor, T.A. Smith-Oliver, W.O. Wilkison, T.M. Wilson, and S.A. Kliewer. 1995. An antidiabetic thiazolidinedione is a high affinity ligand for peroxisome proliferator-activated receptor $\gamma(\operatorname{PPAR} \gamma)$. J. Biol. Chem. 270:12953-12956.

12. Wilson, T.M., J.E. Cobb, D J. Cowan, R.W. Wiethe, E.D. Correa, S.R. Prakash, D.D. Beck, L.B. Moore, S.A. Klewer, and J.M. Lehman. 1996. The structure-activity relationship between peroxisome proliferator-activated receptor $\gamma$ agonism and the antihyperglycemic activity of thiazolidinediones. $J$. Med. Chem. 39:665-668.

13. Tontonoz, P., E. Hu, R.A. Graves, A.I. Budavari, and B.M. Spiegelman. 1994. mPPAR gamma 2: tissue-specific regulator of an adipocyte enhancer. Genes Dev. 8:1224-1234.

14. Tai, T.-A.C., C. Jennerman, K.K. Brown, B.B. Oliver, M.A. MacGinnitie, W.O. Wilkison, H.R. Brown, J.M. Lehmann, S.A. Kliewer, D.C. Morris, and R.A. Graves. 1996. Activation of the nuclear receptor peroxisome proliferator-activated receptor $\gamma$ promotes brown adipocyte differentiation. J. Biol. Chem. 271:29909-29914.

15. Zhu, Y., K. Alvares, Q. Huang, M. Rao, and J. Reddy. 1993. Cloning of a new member of the peroxisome proliferator-activated receptor gene family from mouse liver. J. Biol. Chem. 268:26817-26820.

16. Kletzien, R., S. Clarke, and R. Ulrich. 1992. Enhancement of adipocyte differentiation by an insulin-sensitizing agent. Mol. Pharmacol. 41:393-398.

17. Hotamisligil, G.S., and B.M. Speigelman, 1994. Tumor necrosis factor. A key component of the obesity-diabetes link. Diabetes. 43:1271-1278

18. Ross, S.R., R.A. Graves, and B.M. Spiegelman. 1993. Targeted expression of a toxin gene to adipose tissue: transgenic mice resistant to obesity. Genes Dev. 7:1318-1324.

19. Tokuyama, Y., J. Sturis, A.M. DePaoli, J. Takeda, M. Stoffel, J. Tang, X. Sun, K.S. Polonsky, and G.I. Bell. 1995. Evolution of beta-cell dysfunction in the male Zucker diabetic fatty rat. Diabetes. 44:1447-1457.

20. Sturis, J., W.L. Pugh, J. Tang, and K.S. Polonsky. 1995. Prevention of diabetes does not completely prevent insulin secretory defects in the ZDF rat. Am. J. Physiol. 269:E786-E792.

21. Nakamura, K., and S. Handa. 1984. Coomassie brilliant blue staining of lipids on thin-layer plates. Anal. Biochem. 142:406-410.

22. Burant, C.F., S.K. Lemon, M.K. Treutelaar, and M.G. Buse. 1994. Insulin resistance in denervated skeletal muscle: a model for impaired receptor function coupling. Am. J. Physiol. 247:E657-E666.

23. Laborda, J. 1991. 36B4 cDNA used as an estradiol-independent mRNA control is the cDNA for human acidic ribosomal phosphoprotein PO. Nucleic Acids Res. 19:3998.

24. De Vos, P., A. Lefebvre, S. Miller, M. Guerre-Millo, K. Wong, R. Saladin, L. Hamann, B. Staels, M. Briggs, and J. Auwerx. 1996. Thiazolidinediones repress ob gene expression in rodents via activation of peroxisome proliferator- activated receptor gamma. J. Clin. Invest. 98:1004-1009.

25. Braissant, O., F. Foufelle, C. Scotto, M. Dauca, and W. Wahli. 1996. Differential expression of peroxisome proliferator-activated receptors (PPARs): tissue distribution of PPAR-alpha, -beta, and -gamma in the adult rat. Endocrinology. 137:354-366.

26. Roden, M., T.B. Price, G. Perseghin, K.F. Petersen, D.L. Rothman, G.W. Cline, and G.I. Shulman. 1996. Mechanism of free fatty acid-induced in sulin resistance in humans. J. Clin. Invest. 97:2859-2865.

27. Zhang, Y.R., R. Proenca, M. Maffei, M. Barone, L. Leopold, and J. Friedman. 1994. Positional cloning of the mouse obese gene and its human homologue. Nature. 372:425-432.

28. Fleury, C., M. Neverova, S. Collins, S. Raimbault, O. Champigny, C. Levi-Meyeueis, F. Bouillaud, M.F. Seldin, R.S. Surwit, D. Ricquier, and C.H. Warden. 1997. Uncoupling protein-2: a novel gene linked to obesity and hyperinsulinemia. Nature Genet. 15:269-272.

29. Vidal-Puig, A., G. Solanes, D. Grujic, J.S. Flier, and B.B. Lowell. UCP3: an uncoupling protein homologue expressed preferentially and abundantly in skeletal muscle and brown adipose tissue. Biochem. Biophys. Res. Commun. 291 79-82.

30. Vidal-Puig, A., M. Jimenez-Linan, B.B. Lowell, A. Hamann, E. Hu, B. Speigelman, J.S. Flier, and D.E. Moller. 1996. Regulation of PPAR $\gamma$ gene expression by nutrition and obesity in rodents. J. Clin. Invest. 97:2553-2561.

31. Yki-Jarvinen, H. 1992. Glucose toxicity. Endocrinol. Rev. 13:415-431.

32. Oakes, N.D., C.J. Kennedy, A.B. Jenkins, D.R. Laybuff, D.J. Chisholm, and E.W. Kraegen. 1994. A new antidiabetic agent, BRL 49653, reduces lipid availability and improves insulin action and glucoregulation in the rat. Diabetes. 43:1025-1030.

33. Castle, C.K., J.R. Colca, and G.W. Melchior. 1992. Lipoprotein profile characterization of the KKA mouse, a rodent model of type II diabetes, before and after treatment with the insulin-sensitizing agent pioglitazone. Arterioscler. Thromb. 13:307-309.

34. Storlien, L.H., A.B. Jenkins, D.J. Chisholm, W.S. Pascoe, S. Khouri, and E.W. Kraegen. 1991. Influence of dietary fat composition on development of insulin resistance in rats. Relationship to muscle triglyceride and omega-3 fatty acids in muscle phospholipid. Diabetes. 40:280-289.

35. Shimabukuro, M., K. Koyama, G. Chen, M.-Y. Wang, F. Trieu, Y. Lee, C.B. Newgard, and R.H. Unger. 1997. Direct antidiabetic effect of leptin through triglyceride depletion of tissues. Proc. Natl. Acad. Sci. USA. 94:46374641

36. Levak-Fran, S., R. Herbert, A. Walsh, R. Stollberger, G. Knipping, G. Hoefler, W. Sattler, P. Weinstock, J. Breslow, and R. Zechner. 1995. Musclespecific overexpression of lipoprotein lipase causes a severe myopathy characterized by proliferation of mitochondria and peroxisomes in transgenic mice. $J$. Clin. Invest. 96:976-986.

37. Rossini, A.A. 1985. Lipoatrophic diabetes. In Joslin's Diabetes Mellius. A. Marble, L.P. Krall, R.F. Bradley, A.R. Christlieb, and J.S. Soeldner, editors Lea \& Febiger, Philidelphia, pp. 834-842.

38. Desbois-Mouthon, C., J. Marge, S. Amselem, C. Reynet, M. Blive, M. Goossens, J. Capeau, and C. Besmond. 1995. Lipoatrophic diabetes: genetic exclusion of the insulin receptor gene. J. Clin. Endocrinol. \& Metab. 80:314-319.

39. Robert, J.J., J. Magre, C. Reynet, D. Darmaun, and J. Picard. 1988. In vivo and in vitro characterization of insulin resistance in three cases of lipoatrophic diabetes. Diabetes Metab. Rev. 16:240-247.

40. Inoue, I., K. Takahashi, S. Katayama, Y. Harada, K. Negishi, A. Itabashi, and J. Ishii. 1995. Effect of troglitazone (CS-045) and bezafibrate on glucose tolerance, liver glycogen synthase activity, and $\beta$-oxidation in fructosefed rats. Metab. Clin. Exp. 44:1626-1630. 